\title{
Design and evaluation of a smart home voice interface for the elderly - Acceptability and objection aspects
}

\author{
François Portet · Michel Vacher · Caroline Golanski · Camille Roux · Brigitte \\ Meillon
}

Received: date / Accepted: date

\begin{abstract}
Smart homes equipped with ambient intelligence technology constitute a promising direction to enable the growing number of elderly to continue to live in their own homes as long as possible. However, this calls for technological solutions that suit their specific needs and capabilities. The SWEET-HoME project aims at developing a new user friendly technology for home automation based on voice command. This paper reports a user evaluation assessing the acceptance and fear of this new technology. 8 healthy persons between 71 and 88 years old, 7 relatives (child, grandchild or friend) and 3 professional carers participated in a user evaluation. During about 45 minutes, the persons were questioned in co-discovery in the DomUs smart home alternating between interview and wizard of $\mathrm{Oz}$ periods followed by a debriefing. The experience aimed at testing four important aspects of the project: voice command, communication with the outside world, domotics system interrupting a person's activity, and electronic agenda. Voice interface appeared to have a great potential to ease daily living for elderly and frail persons and would be better accepted than more intrusive solutions. By considering still healthy and independent elderly people in the user evaluation, an interesting finding that came up is their overall acceptance provided the system does not drive them to a lazy lifestyle by taking control of everything. This particular fear really needs to be
\end{abstract}

This work is supported by the Agence Nationale de la Recherche (ANR-09-VERS-011)

François Portet, Michel Vacher, Caroline Golanski, Camille Roux and Brigitte Meillon

UJF-Grenoble 1 / Grenoble-INP /UPMF-Grenoble 2 / CNRS, Laboratoire d'Informatique de Grenoble UMR 5217, Grenoble, F-38041, France

Tel.: +33 (0)4 76635573

Fax: +33(0)476635552

E-mail: Francois.Portet@imag.fr addressed for the development of smart homes that support daily living without imposing an unhealthy way of life.

Keywords Voice Interface $\cdot$ Smart Home $\cdot$ Ubiquitous Computing $\cdot$ User Evaluation

\section{Introduction}

Evolution in ICT led to the emergence of smart homes which offer new opportunities to improve people's in-home comfort by providing increased communication, awareness, and functionality. One of the main recognized application domains of smart homes is the assistance of people with disabilities and of the growing number of elderly people which, according to the World Health Organization (WHO), is going to reach 2 billion by 2050 . One of the first wishes of this population is to be able to live autonomously as long as possible as comfortably as possible and to age well. Within the smart home domain, this concept is known as Ageing-InPlace [31] and consists in allowing seniors to keep control of their environment and activities to improve their autonomy, health, well-being and their feeling of dignity. Moreover, independent living is also known to reduce the cost to society of supporting people who have lost some autonomy [15].

Smart homes were first designed more than a decade ago as a way to fulfil this aim and nowadays have become a very active research area [8]. Several technologies have been used to set up a smart environment able to ease the person's life and to provide adequate assistance. Audio-based technology has a great potential to become one of the major interaction modalities in smart home and more generally in 'Ubiquitous Computing'. As introduced by Weiser [49], ubiquitous computing refers to the computing technology which disappears into the background, which becomes so seamlessly integrated into our environment that we do use it naturally without noticing it. Audio technology has not only reached 
a stage of maturity (e.g., automatic speech recognition is a feature of many computers and mobile applications) but has also many properties that fit this vision. It is physically intangible and depending on the number and type of the sensors (omnidirectional microphones) that are used, it does not force the user to be physically at a particular place in order to operate. Moreover, it can provide interaction using natural language so that the user does not have to learn complex computing procedures or jargon. It can also capture sounds of everyday life which makes it even more easy to use (hand clapping to control light is a well known example) and can be used to communicate with the user using synthetic or prerecorded voice. Despite all this, a relatively small number of smart home projects have seriously considered audio technology and notably speech recognition in their design [14, $3,17,30,11,28]$. Part of this can be attributed to the fact that this technology, though mature is still complex to set up in a real environment and to the fact that important challenges still need to be overcome [48].

To improve autonomy, comfort and security at home, we are developing a new smart home system called SWEETHOME whose main man-machine interaction modality is based on audio processing technology. Many projects are devoted to the support of physically or cognitively impaired elderly. In our project, the targeted users are elderly people who are frail but still autonomous. The rationale behind this choice is that a home automation system is expensive, so it would be much more profitable if it can be used to accompany daily life rather than only when the need for assistance appears. Moreover, if the user's situation changes (e.g., wheelchair, cognitive decline), the system could be adapted and specific assisting technologies could be 'plugged-in' to adapt the environment to the user and not to suddenly impose a completely new way of life to the user by fitting her house with ICT. This kind of user has still not received much attention from the smart home community. Elderly people are indeed often frail but that does not always mean they are highly dependent or they are not able to make decisions. Particular attention should be paid to the type of assistance to be provided since scientific studies have shown that the reduction of sense of control in the elderly population may have a significant adverse effect on their health [41]. Thus, user evaluations in the domain of AAL (Ambient Assisted Living) are not completely adapted to the population considered in this study nor those involving young participants.

According to these considerations, before building the SwEET-Home system, the question is Would a independent elderly person and her family be interested in this technology? What will make it acceptable? What are their needs at this stage of their life? The aim of the study reported in this paper is to answer these questions by conducting a user evaluation. The experiment consisted in asking elderly users to perform realistic tasks in a realistic smart home environ- ment. After a short review of the literature in Section 2, Section 3 provides details about the SWEET-HOME project and its development strategy. In Section 4, the experimental design is described. It consists in a Wizard of $\mathrm{Oz}$ experiment with interviews of elderly people and their relatives in codiscovery. Particular attention has been paid to the opinion of the close social environment of the elderly. The results of this experiment are presented in Section 5 and the main findings are discussed Section 6.

\section{State of the Art}

Many studies have been conducted in different countries to define the needs of elderly concerning a smart home system able to help them in their daily life [26,34,9, 23, 7, 51]. These studies concern systems that provide support in three main areas: Health monitoring, Security and Comfort. Health oriented systems are those which monitor the status of the person (e.g., weight, heart rate, activity) via physiological sensors, movement detector, videos, etc.; Security oriented systems provide distress or hazardous situation detection, for instance, fall detection, smoke detection, intrusion detection, etc.; and Comfort oriented systems based on classical home automation allowing people to manage home appliance in an easy way.

A number of quality measures were identified in these studies that fall under two major categories: acceptability (Usability, Affordability) and trustworthiness (Safety, Security, Reliability, Privacy). However, as pointed out in [1], it is difficult to define an unique criterion about user acceptability given the diversity of users and applications considered. Thus, these studies are difficult to compare. Furthermore, some studies used quantitative evaluations others qualitative ones with large samples of persons or small focus groups composed of young or elderly persons. For instance, in [17] the aim is to develop a Personal Emergency Response System using voice interaction which was tested with only 9 healthy young people. In [7], 200 Spanish people between 50 and 80 years old were questioned about different features of a smart home, but these persons were not confronted to a prototype system. In [26], three user interfaces were tested in a smart home in Finland. After a focus group study, a real house equipped with all the functionalities under consideration was used to collect six months of data. However, the data contains information about only one young couple and thus gives no insights into the needs of a senior living alone.

Regarding the experimental setting, most of the studies which included a prototype were conducted in temporary spaces fitted with sensors or in a real in-lab flat built for the laboratory. Very few experiments have actually been conducted within the persons' own homes with the notable exception of [34]. In fact, the smart home domain is still recent 
and to the best of our knowledge there is no standard procedure that has emerged. In [25], user evaluations were categorised into: in-situ (in the real environment of the user), invitro (in laboratories) and in-sitro/in-simu (in a simulated environment reproducing the user's environment) according to the experimental environment the user is put into. This was further expanded by [22] who also classify settings according to the task (see [22] for more details). As pointed out by $[25,22]$, in-vitro experiments are highly controlled but correspond poorly to the user's reality while in-situ experiments are supposed to provide very realistic data by considering the actual user's context of the pervasive system, but may be highly biased by the observers (e.g., camera, experimentators around, measurement devices) and can be extremely costly. In-sitro/in-simu experiments consist in substituting a synthetic environment for a real one in order to work under laboratory conditions of control. This experimental setting showed that it can identify most of the same usability problems as found in the other conditions though it did not revealed all the realistic aspects of an in-situ condition [25, 22]. Given the complexity of the smart home domain and the importance of taking into consideration the user's own context, in-sitro/in-simu setting is particularly suitable to the smart home domain at the prototyping level. Of course, the frontiers between the different settings are fuzzy and actually, many smart home user evaluations can be considered as having some aspects of an in-simu setting. Despite this diversity in experimental settings, aims, criteria, targeted users and technologies, results of these studies show convergence to some frequently expressed needs which are described as follows.

Security The main need expressed by the elderly people in the studies is related to security [26]. What causes a major feeling of insecurity is the fear of falling which is prevalent in this category of population. As reported in [18], in community-dwelling populations, about one-quarter of USA citizens aged 65 to 74, and more than one-third of those aged 75 and older, report a fall in the previous year. Accidents most feared after falls are the ones linked to gas and to fire [23]. The persons fear forgetting to turn off gas, tap, oven, etc. Another great fear is that of a criminal entering the house due to a badly closed door or because this intruder was not correctly identified. According to this, a system which would meet the elderly needs would be a system: able to detect a possible fall and to contact quickly a person to help them, able to detect dangerous situations (e.g., gas not shut off) and, able to give reassurance about who can enter into their home. Audio technology can play a leading role in smart homes by providing the person in danger with a way to call for help from anywhere in the house without having to use a tactile interface that may be out of reach. Promising research has been done to detect distress situations from speech [20] and to detect a fall using microphone [36]. One example of such a trend is the dialogue system developed by [17] to replace the traditional worn emergency systems that requires too much change in the senior's lifestyle by imposing them to wear the device at all time and which are prone to generate too many false alarms.

Health Monitoring Apart from falls, dedicated smart homes called health smart home [39] can monitor the health status of the person to predict dangerous situations, to recognize a subtle change in activity [27], to promote healthy behaviour and to train the person (e.g., cognitive exercises). The health smart home concept can offer a large variety of services that may be highly intrusive (e.g., physiological sensors to be worn $24 \mathrm{~h} /$ day) or smoothly integrated in the home (e.g., automated blind control to avoid difficult movement). Examples of medical services which use audio processing technologies are some medication reminder systems [38,5]. In [38], an Intelligent Voice Responder (IVR) was set to call participants at prescribed times to remind individuals to take or refill medications. Another application is described in [12], in which a variety of sensors, including microphones, were used to detect the activity of daily living (ADL) with the ultimate goal of detecting a loss of autonomy. In this application, audio information has proven to be essential to detect some of these ADLs [46]. Non-speech audio data has also been showed to be particularly interesting to locate persons when only a reduced set of sensors is used together with microphones [?].

Proactivity A study conducted in Spain by [7] among 200 men and women aged 50-80 years showed an interest in a proactive and multimodal management of the following features: light (system ability to control light using multimodal commands), heat (ability to adjust the house temperature remotely), windows and shutters (managing the opening and closing of the blinds), kitchen (control of oven, refrigerator, washing machine) and contact (system ability to function as a phonebook). However, in [34], a 3-year study in the participants' actual house showed that there is considerable resistance towards the increase of proactive information technology in homes. As pointed out in another long term study (6 months) [26], participants did not get used to the fact that the home could "live a life of its own". Thus, [34] recommends to embed proactive technology as seamlessly as possible within the users' environment without perturbing their way of living. Of course, many actions can be performed pro-actively by the smart home but the degree of perturbation varies with the kind of the action and the context in which this action is performed (e.g., heating control vs. dialling a phone number without the user's order).

Usability Regarding the usability, many persons have expressed some apprehension towards smart home technolo- 
gies because they fear not being able to use them. The system should be easy to use, easy to learn and resilient to errors $[34,7]$. As listed by the Digital Accessibility Team (DAT) ${ }^{1}$, smart homes can be inefficient with disabled people and the ageing population. Visually, physically and cognitively impaired people will find very difficult to access equipments and to use switches and controls. This can also apply to ageing population though with less severity. Thus, apart from hearing impaired persons, one of the modalities of choice is the audio channel. Indeed, audio processing can give information about the different sounds in the home (e.g., object falling, washing machine spinning, door opening, foot step...) but also about the sentences that were uttered (e.g., distress situations, voice commands). This is in line with the DAT recommendations for the design of smart home which are, among other things, to provide hands free facilities whenever possible for switches and controls and to provide speech input whenever possible rather than touch screens or keypads. Moreover, speaking is the most natural way for communication. Audio interfaces are thus a priori highly usable by many kinds of person in many situations [43].

Dependence/Confidence In some studies, people expressed their concern about being dependent on such a system, especially in case of failure. Many elderly fear that the system would break down and leave them in a critical situation by having made them dependent on the system [34,7]. In [34], the participants emphasized that they wanted to keep control of their domestic spaces regardless of the conveniences the new technology would make available. Actually, they expressed the wish that new technologies should provide a way to be switched off so that the user always keeps control. The controllability of the smart home seems to play a crucial role for its acceptability [51]. A smart home would thus provide much reinsurance if it provides several ways of being controlled. In [26], among the three different interfaces provided to control a domotics system (mobile phone, media centre on TV or centralised controller on a PC) the mobile phone was the most used, but participants did use all the interfaces to control the house during the 6-month study. The study showed that the interfaces were more adapted to specific classes of actions. For instance, the mobile phone was more adapted to instant control (i.e., do this right now!) than pattern control (i.e., task automation) which was generally set using the centralised PC. The authors also pointed out that the confidence in new technology is gained through the use of it, but, in general, participants were using some interfaces because they were able to check the results. Audio interfaces should thus be conceived in complement of others ways of controlling the environment and should provide adequate feedback to the user.

\footnotetext{
1 http://www.tiresias.org
}

Privacy/Intrusiveness Some people have expressed the wish that all these technologies do not interfere with their daily activities and that the system is as invisible as possible [34]. In general, the participants would like to interact as little as possible with the system. It is important to note that many systems, in particular fall detectors, are relying on video cameras [24,52], but little is known about the acceptance of such sensors by the intended users who are not always included in the system design. For the elderly, there is a balance between the benefit of such monitoring (sensors in all genres) and the intrusion into privacy. A recent study [40] showed that the degree of acceptance of intrusive technology varies with the severity of the pathology of the elderly person being supported [1]. This was also confirmed in [51] where most of the 82 interrogated persons did not think that the inconspicuousness of the system was an issue. But this study was focussed only on medical applications for which, a stated before, the vital benefit of it makes acceptable some changes in daily life. Another aspect of privacy which is emerging is what will be made of collected data. Since the system receives information of vital importance, the system has to be protected against intrusion and has to make sure that the information reaches only the right people. Smart homes design must thus be respectful of privacy and should provide reinsurance regarding who is going to access the collected private data.

Voice Interface A certain number of studies about audio technology in smart home have been conducted. This includes speech recognition [46], sound recognition [46,42], speech synthesis [29] or dialogue [14,17,30]. A few opinions were collected regarding the elderly interest toward voice interaction $[7,26]$. In a recent study [7], people were interested in the voice command to activate the closing of windows and blinds as well as for setting television and radio. These studies also related that $95 \%$ of the persons would continue to use the system even if it is sometimes wrong in interpreting orders. In [26], voice command is used for interaction during the accomplishment of small tasks (kitchen mainly). For instance, it would make it possible for someone to answer the phone while cooking. The interviewees expressed their fear about a system that does not recognize what they say. According to the authors, this fear is certainly due to the user's experience with speech interfaces for their mobile phones. These studies showed that the audio channel is a promising area for improvement of security, comfort and assistance in health smart homes [48], but it remains relatively unexplored compared with classical and mobile physical commands (switches, remote control, PDA, mobile phone).

One common outcome of all these studies is that, whatever the technology being considered, no smart home application is going to be successful if the intended users are not 
included in the design of the system [34,13,7,1]. Acceptability is the key factor to integrating new technologies in homes, particularly when the users are elderly or low ICT educated persons. Without proper assessment of the user needs, fears and expectations, assistive technologies may be developed in vain.

\section{SWEET-HOME}

The SWEET-HOME project ${ }^{2}$ is a French national supported research project [47]. The project team is made up of researchers and engineers from the Laboratory of Informatics of Grenoble (specialised in speech processing, smart home design and evaluation), from the Esigetel (specialised in audio technology) and from three companies: Theoris (realtime system development and integration), Camera Contact (diffusion and integration of adapted services for maintenance at home) and Technosens (remote assistive equipment for the elderly). The project aims at designing a new smart home system and focuses on three main aspects: to provide assistance via natural man-machine interaction (voice and tactile command), to ease social inclusion and to provide security reassurance by detecting situations of distress.

The main impacts of the system would be to improve autonomy, comfort and security at home. The project is not strictly health oriented because it does not primarily aim at assisting highly cognitively or physically disabled persons. The target population is elderly people. In France, the number of people over 60 years old is expected to reach $28.4 \%$ of the population in 2020 (9.4\% will be $>75)$ and $32.6 \%$ in 2060 (when $16.2 \%$ will be $>75$ ) compared with $21.5 \%$ of over 60 s in 2007 [6]. Solutions to enable this population to live as long as possible in their own home must thus be found. As pointed out by [50], in the case of persons with various pathologies, a designed-for-all smart home approach may be inappropriate given that each person would have specific needs. However, basic health support can be defined in smart homes that can be complemented and personalised to the need of the user. In SWEET-HOME, the approach is to design a system to improve security and comfort that can be continuously adapted to the person's degree of autonomy throughout her life. This multiple purpose life-long solution seems a better model than specific on demand solutions both at the level of user familiarisation and at the financial level.

The SweET-Home system is depicted in Figure 1. The input of the system is composed of the information from the domotics system transmitted via a local network and information from the microphones transmitted through radio frequency channels. While the domotics system provides symbolic information, raw audio signals must be processed to extract information from speech and sound. This extraction

\footnotetext{
2 http://sweet-home.imag.fr/
}

is based on the AUDITHIS system [46] a real time multithreaded audio processing system for ubiquitous environments. The extracted information is analysed and either the system reacts to an order given by the user or the system reacts pro-actively by modifying the environment without an order (e.g., turns off the light when nobody is in the room). Outputs of the system include domotics orders but also interaction with the user in the case when a vocal order was not understood for example, or in case of alert messages (e.g., turn off the gas, remind the person of an appointment). The system should also make it easier for the user to connect with her relatives, physician or caregiver by using the e-lio ${ }^{3}$ or Visage ${ }^{4}$ systems. In order for the user to be in full control of the system and also in order to adapt to the users' preferences, three ways of commanding the system are possible: voice order, tablet computer or via classical tactile interfaces (i.e., switches).

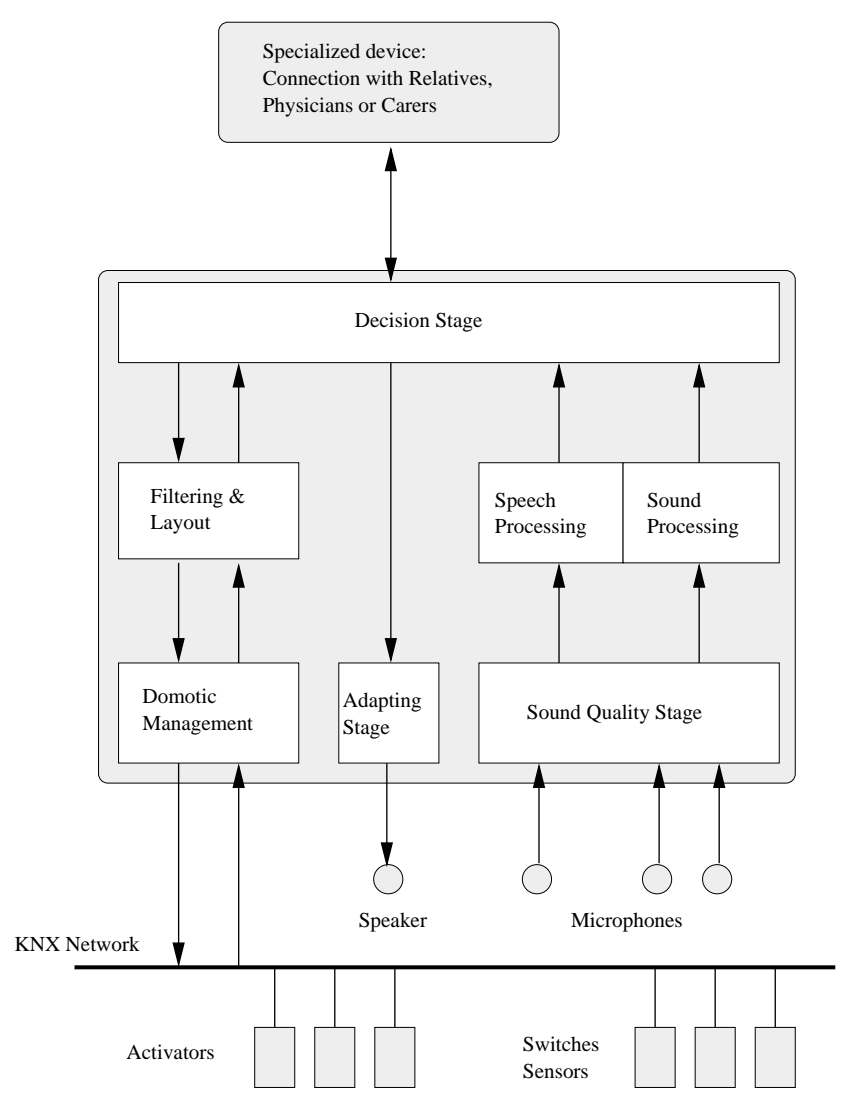

Fig. 1 The Sweet-Home diagram

The project does not include the definition of new communication protocols between devices. Rather than building communication buses and purpose designed materials from scratch, the project uses already standardised technologies and applications. As emphasized in [34] (whose authors

\footnotetext{
3 www.technosens.fr

4 camera-contact.com
} 
used X10 for their home automation bus), standards ensure compatibility between devices and ease the maintenance as well as orient the smart home design toward cheaper solutions. The interoperability of ubiquitous computing elements is a well known challenge to address [10]. Another example of this approach is that SWEET-HOME includes systems which are already specialised to handle the social inclusion part. We believe this strategy is the most realistic one given the large spectrum of skills that are required to build a complete smart home system.

The main aspect of the system development is to make it highly acceptable and usable. Of course, other criteria are considered such as adaptivity, pro-activity, reliability, but our key contribution relies on the natural interaction with the environment via the voice interface. The acceptability criterion is highly linked to the human user, thus classical machine centred design is not adapted to constraints other than technological and functional ones. A Human-centred computing [21] approach must be adopted in order to always keep the user in the development loop. In that way, user's capacities, preferences and fears are taken into account not only at the beginning and end of the project but also during its development. As pointed out by [13], the involvement of prospective users is an essential prerequisite for the development of assisting technology. This is even more important in a pervasive environment because it is a relatively new area for which all the possibilities of ubiquitous computing for smart homes are still not completely defined.

The development of SWEET-HOME follows the diagram given in Figure 2. The first step consisted in making a set of requirements based on our expertise in smart environments, our expertise on health-care and social equipment for the elderly and on user surveys from the literature [10,26,9,23, $34,13,40,7]$. This made it possible to draw up a first list of specifications of the system which was used to design its functionalities and methods of interaction. The Wizard of $\mathrm{Oz}$ (WOZ) step consists in confronting the potential users with a system that they believe to be automatic, but which is actually being operated by an experimenter [22]. This provides feedback from the users in a realistic situation. The feedback and suggestions are then incorporated into the design. After the WOZ, the various features of the SwEET-HomE system will be developed independently in a more machine centred way (i.e., making it work) but including human users in the loop as much as possible (i.e., making it easy to use). When developed, all the functionalities will be integrated together with the domotics environment and this real system will be again tested with the targeted users and adapted and corrected if necessary. This paper reports the results of the WOZ experiment.

\section{Experimental Design}

The SwEET-Home concept was evaluated during a dedicated Wizard of OZ experiment and interviews that lasted 4 weeks between April and May 2010 in the Domus Smart Home. Seniors, their relatives and professional carers were interviewed and were interacting with the system during about 45 minutes. Regarding the elderly and their relative, the interviews were semi-directive (open questions) and held in co-discovery (participants were always grouped by couple). The functionalities of the system to assess were presented to the participants one after another and each participant had time to discover them before being questioned and before the WOZ interaction. The WOZ interaction consisted mainly in the control of the environment. For instance, if the participant said "close the blind", the blind were closed remotely. This section describes the target users that were recruited, the smart environment in which the experiment was performed, the functionalities assessed, and the experimental protocol.

\subsection{Participants}

The participants consisted of 18 persons from the Grenoble area. They were divided up into three groups: elderly $(n=8)$; relatives $(n=7)$ - composed of mature children, grandchildren or friends-; and caregivers $(n=3)$. Table 1 summarises the participants' characteristics.

Table 1 Summary of the participants' characteristics

\begin{tabular}{llllll}
\hline gender & age & relationship & visit frequency & PC & Internet \\
\hline $\begin{array}{lllll}\text { female } \\
\text { female }\end{array}$ & 88 & $\begin{array}{l}\text { grand-mother } \\
\text { grand-daughter }\end{array}$ & $1 /$ week & No & No \\
female & 81 & grand-mother & $1.5 /$ week & No & No \\
male & 19 & grand-son & & Yes & Everyday \\
\hline female & 82 & grand-mother & $3 /$ week & No & No \\
female & 25 & grand-daughter & & Yes & Everyday \\
\hline male & 76 & uncle & $1 /(3$-week $)$ & No & No \\
female & 56 & niece & & Yes & Everyday \\
\hline female & 75 & friend & rare & Yes & Everyday \\
female & 70 & friend & & Yes & Everyday \\
\hline female & 75 & grand-mother & $7 /$ week & No & No \\
male & 22 & grand-son & & Yes & Everyday \\
\hline male & 71 & & $1.5 /$ week & No & $2 /$ week \\
\hline male & 86 & neighbour & $1 /$ week & No & No \\
female & 51 & neighbour & & Yes & Everyday \\
\hline & & & & &
\end{tabular}

The mean age of the elderly group was $79.0(\mathrm{SD}=6.0)$, and 5 out of 8 were women. These persons were single and perfectly autonomous. The frequency of visit by their relative was from once a week to everyday. The majority did not have a computer (except one) and did not consult Internet often. Professions were diverse: dressmaker, engineer, 


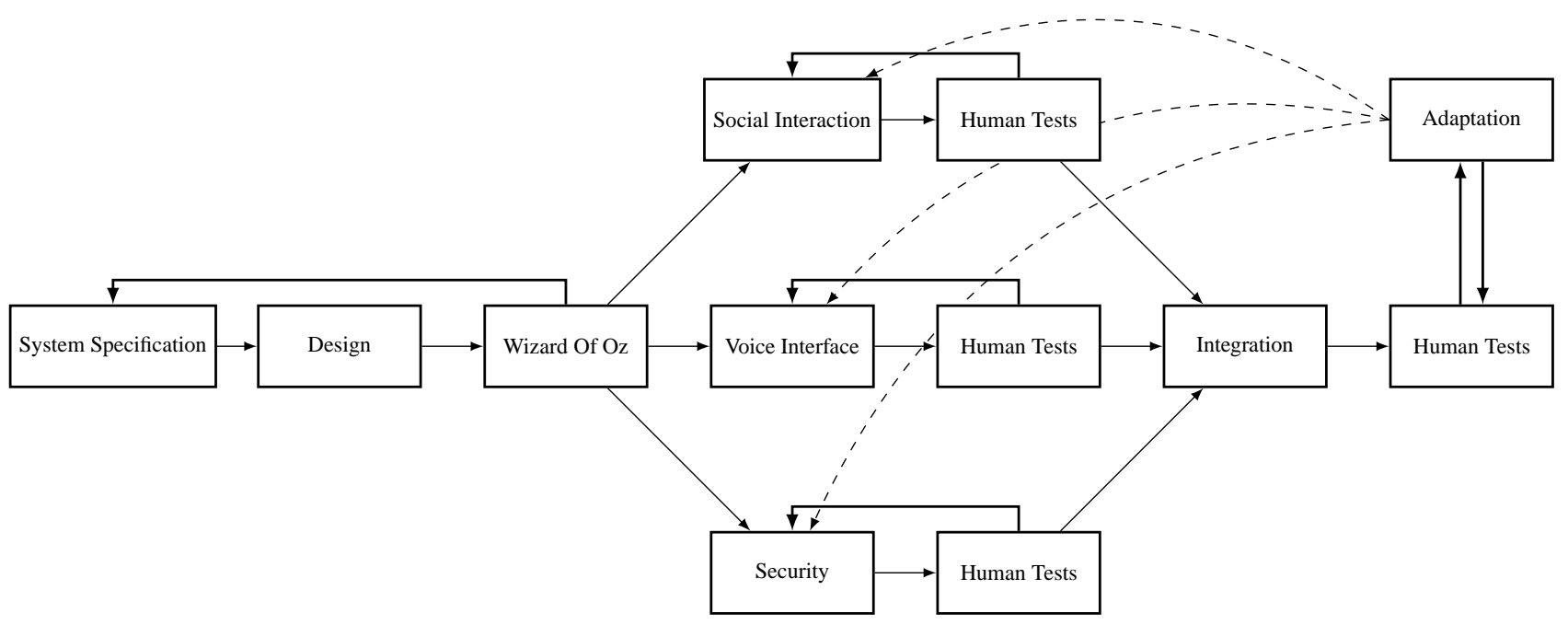

Fig. 2 Development of the SweEt-Home system

teacher, accountant, secretary, and farmer. The mean age of the relative group was $41.0(\mathrm{SD}=19.5)$, and 5 out of 7 were women. Their relationship with their elder partner varies but they were chiefly grandchildren (4/7).

In order to acquire another view about the interest and acceptability of the SWEET-HOME system, 3 professional caregivers were also recruited to participate in the experiment. This group was composed of 2 nurses and one professional elderly assistant. These people were mainly recruited to give a general point of view about how elderly persons and their relatives could accept the system and how such a system could also facilitate their daily work.

\subsection{The Domus Smart Home}

The Domus smart home was designed and set up by the Multicom team of the Laboratory of Informatics of Grenoble, France. This smart home is dedicated to the observation and the measurement of users' interactions with the ambient intelligence of the environment. Figure 3 shows the details of the flat. It is a thirty square meters suite flat including a bathroom, a kitchen, a bedroom and a study, all equipped with sensors and effectors so that it is possible to act on the sensory ambiance, depending on the context and the user's habits. The flat is fully usable and can accommodate a dweller for several days.

The technical architecture of Domus is based on the KNX bus system ${ }^{5}$, a worldwide ISO standard (ISO/IEC 14543) for home and building control. Bus devices can either be sensors or actuators needed for the control of building equipments such as: lighting, shutters, security systems, energy

\footnotetext{
5 www.knx.org
}

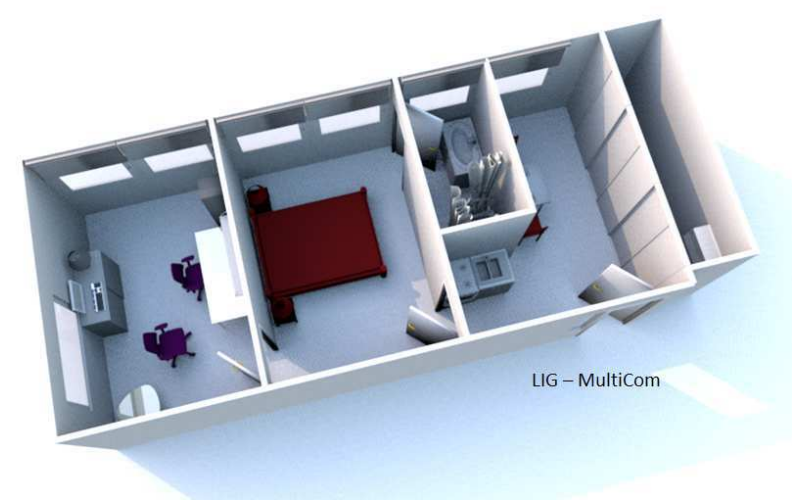

Fig. 3 The Domus Smart Home

management, heating, ventilation and air-conditioning systems, interfaces to service and building control systems, remote control, metering, audio video control...

Besides KNX, several field buses coexist in DoMUs, such as UPnP (Universal Plug and Play) for the audio video distribution, X2D for the opening detection (doors, windows, and cupboards), RFID for the interaction with tangible objects (not used in the SWEET-HomE project). More than 150 sensors, actuators and information providers are managed in the flat. A residential gateway architecture has been designed, supported by a virtual KNX layer seen as an OSGI service (Open Services Gateway Initiative). This layer guarantees the interoperability of the data coming from the different field buses and allows the communication between them and towards virtual applications, such as activity tracking. More than 60 bundles delivering more than 60 services are running. Thanks to this gateway, all domotics elements as well as multimedia elements can be controlled and parametrised remotely. 
For the need of the SWEET-HOME project, the flat has also been equipped with 7 radio microphones set into the ceiling ( 2 per room except for the bathroom) that can be recorded in real-time thanks to a dedicated PC embedding an 8-channel input audio card [46].

\subsection{Protocol}

Each test was composed of an interviewer, a wizard (an experimenter hidden in the technical room of DomUs operating the domotics system remotely) and a couple of one elderly person with a relative (except for one senior who was alone). The participants and the interviewer were inside the smart home during the whole test except during some parts of the scenarios during which the relative moved to another room (e.g., video-conferencing). Figure 4 shows a typical situation where a 75-year old lady and her grand son are being interviewed by an experimenter. All interviewees were recorded on video and audio and specific consent forms were signed by all participants.

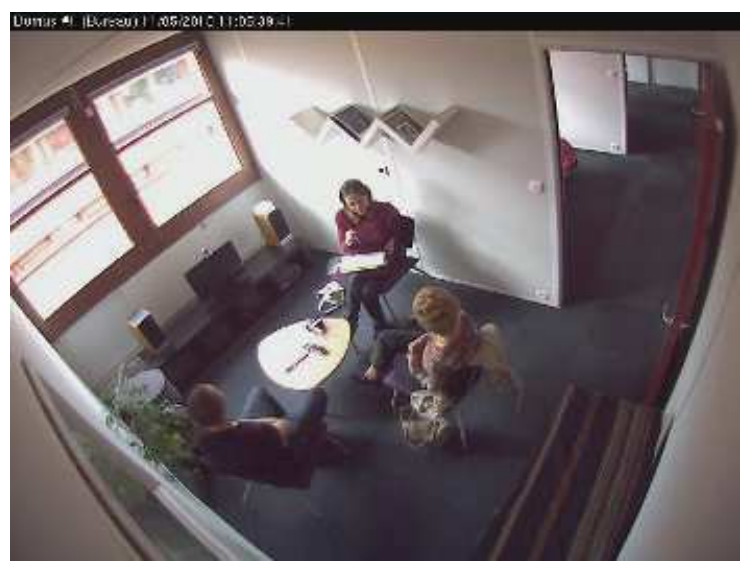

Fig. 4 Picture of a typical interview within the Domus Smart Home

The co-discovery approach was chosen to reassure the senior about the experimental context (new environment, experimenter, etc.) thanks to the presence of their relative. Moreover, it eased the projection of both participants into the new system because they could exchange points of view (e.g., the relative can remind the senior of a previous discussion they had had related to some aspects of the system). Of course, the relationship between the two people can also influence the experiment (e.g., a grand mother who would not like to expose her weakness to her grand son) that is why some short periods were planned during which the participants were interrogated separately. Regarding the professional caregivers, they were interviewed separately.

The aim of this study was to assess the acceptability of the SWEET-Home system. But, there is no standard definition about user acceptability in this domain [1]. Users can reject a new technology because it is too complex, too intrusive, not natural, does not fit their education or religion, does not meet their needs, etc. Thus, most of the experiment was conducted to find out whether the potential users would appreciate the new functionalities brought by the system (e.g., 'Do you appreciate making the system operate using your voice? Why?', 'Do you find this natural?'). Moreover, in order to guide the development of the system, aspects of usefulness, usability, personalisation (how one wants to speak to the house), interactiveness (interaction modalities such as voice, tactile or remote control), proactiveness (when the system decides to act without human intervention), intrusiveness (disruption in the middle of an activity), social interaction, and security were investigated.

The protocol has been defined by two experienced ergonomists (usability engineers), one of which was also the interviewer. The experiment was clearly separated into four scenarios each of them concerning a unique theme to avoid any confusion, and ended with a short debriefing. In each of these scenarios, the elderly person was asked to interact with the environment and to answer questions related to this interaction. This made it possible to directly illustrate the technology being evaluated rather than trying to explain verbally the concept in a technological language that may not be understandable by the participants. Questions were defined using an simple language in order to be perfectly understood by all the participants.

The first scenario was about the voice command aspect of the SWEET-Home project. Both the senior and her relative were present in the room. The senior was asked to control blinds, lights and the coffee machine using her voice without any recommendation about how to do it. This consisted in talking "to the home". The vocal order given was followed by the proper action in the home operated by the hidden wizard. For each participant an incomprehension of the system was simulated. The participants were also interrogated about whether a remote control having a microphone embedded in it would be a better interaction method. Then, questions regarding the naturalness and easiness of the voice command were asked to both persons. Finally, the senior stayed in the smart home with the interviewer while the relative was taken to another room and questions regarding the preferred form of interaction were asked to both separately. For instance, "Do you prefer to talk to a remote control or to the house in general?" "Would you rather use the 'vous' form (formal) or the 'tu' form (familiar) when uttering an order?"

The second scenario consisted in using technology for communication with the outside. The senior was left alone in the smart home watching a TV program, when suddenly the face of the relative appeared on the screen and they started a conversation. After the conversation, the senior was re- 
joined by her relative and the interviewer. Questions were asked about their own preferences.

The third scenario focused on system interruption. The couple and the interviewer were talking in the smart home when the system interrupted them via a pre-recorded voice played through the speakers, calling for a door to be closed or the cooker to be turned off. After this, questions related to whether being interrupted by the system was acceptable or not and how the interruption should happen were asked. Also, the problem of security in general and how such system could enhance security was discussed with the couple.

The fourth scenario consisted in investigating the usefulness and acceptability of a shared electronic calendar. After an introduction to the product, the participants were asked whether they would accept such a tool and to which extend they would be ready to share it with other people.

This experiment has been designed to be an in-sitro/insimu scenario oriented user evaluation which is one of the best compromises between pure in-lab and in-situ experiments when the system under evaluation is at the prototyping level (see [22] for more detail).

\section{Results}

This section summarises the results of the study for the 4 scenarios: voice command, interruption by the system, communication with the exterior and shared electronic calendar. In the remaining of this paper, answers from the group of seniors are generally reported both in original French and with their English translation because some cultural phrases are difficult to translate. Relatives and professionals answers are only reported translated in English for readability.

Interaction With the Smart Home Using Speech The first part of this scenario was to make the seniors ask the home to activate a domestic device (light, coffee maker) using their voice, without giving them any recommendation about how to do it. It is interesting to notice that five out of eight people naturally emitted sentences: "C'est l'heure de baisser les volets" ("It's time to lower the blinds"), "Il faut rallumer la lumière" ("The light must be put on again"), "Que la lumière soit !" ("Let there be light!"). The other seniors spontaneously uttered orders using keywords such as "lower blinds" or "coffee start". Although most of the older people $(5 / 8)$ spontaneously controlled the home by uttering sentences, after the test, the majority (5/8) said they wanted to control the home using keywords. They believe that this mode of interaction would be the quickest and the most efficient. The most interesting comments were:

\footnotetext{
- "Le plus court c'est le mieux." ("The shorter the better.")
}

- “Dans un premier temps c'est des phrases et ça deviendrait des mots clés.”

("At first, sentences and then it would become key words.")

- "J'aimerais mieux faire des phrases mais je suis une littéraire. [...] Pour le moment ça m'amuse les phrases, peut-être qu'à un moment ça m'amusera plus."

("I would rather speak using sentences but I am a literary person. [...] Right now, it's amusing using sentences but may be after a while that would not be fun any more.")

- "Pour moi je dirais des mots clés. Des mots brefs on les oublie moins facilement."

("For me I would say keywords. Short words are less easily forgotten.”)

Only half of the seniors found it natural to interact by voice even though some admitted speaking aloud when they are alone. In contrast, almost all the relatives (6/7) found the voice interaction natural. The answers are summarised in Figure 5. Some relatives also emphasized the fact that older people have a tendency to speak aloud when they are alone.

In a second part, seniors were asked about commanding elements of the home using a dedicated physical device. Most of the elderly people (6/8) said they would prefer to speak to the home rather than to a remote control or robot companion ("The best is to talk like this that avoids to have a device"). But it should be noticed that we did not have these robotic pets. People might have been more positive towards such objects if they had been able to handled them. However, two persons said they would prefer to speak to a remote control because the sound recording would be better (they would not have to speak loudly) and because the object induces the notion of dialogue "Maybe the little robot, if it makes sentences, I mean if it speaks.”

In the tests, misunderstandings of the system were simulated twice. At one point, when the elderly person uttered an order, the home answered "I did not understand your request, can you repeat please?" using a pre-recorded voice. Almost all seniors did not find it annoying that the system asks them to repeat orders. However, they stressed that they would not tolerate it if it happened too often. In case of misunderstanding, most seniors (6/8) preferred that the system asks them to repeat rather than proposes a choice between several solutions.

Almost all seniors (7/8) appreciated the possibility of controlling the house using voice commands. However, these same seniors do not plan to use such system at present. They think this way of interacting is devoted to people with disabilities. The elderly are afraid of being considered as a dependent person if they decide to adopt this system at home. They also fear of losing autonomy because of the system. The following comment of one senior summarises the global trend: 


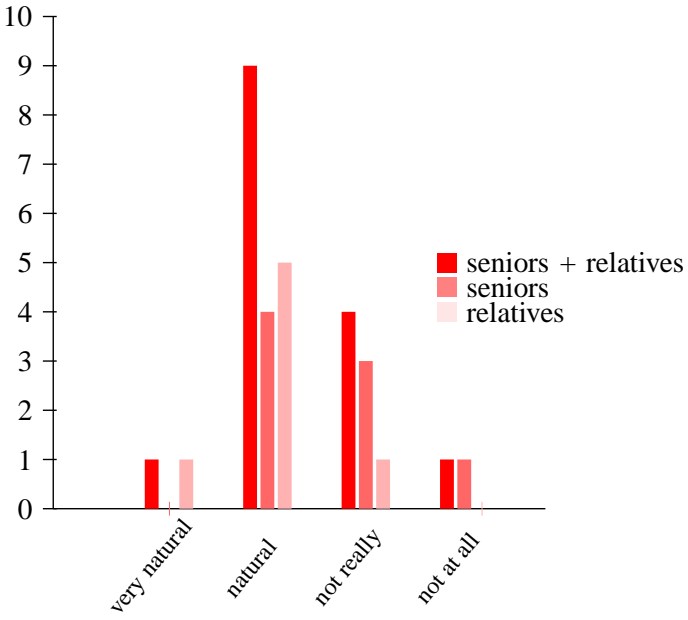

Fig. 5 Answers to the question "do you find voice interaction natural?"

"Mais alors on fait plus rien, c'est une chose de fainéant, c'est une vie de fainéant et puis quand on est vieux, moins on en fait plus on s'encroûte, c'est pas bon hein! Pour quelqu'und'handicapé d'accord ce serait épatant. Mais moi pour le moment ça ne m'intéresse pas."

("But then you don't do anything anymore, it's a thing for lazy people, it's a lazy life and then when you're old, the less you do the more you get in a rut, it's not good eh! For someone with a disability, I agree it'd be great. But for now I'm not interested.")

One person was even highly against this kind of system: “Je me vois pas avec des appareils comme ça, pas du tout du tout du tout! [...] je n'arrive pas à me mettre à ce niveau là. Là [parler à la maison] j'ai l'impression qu'on a l'air gadio [=bête]."

("I do not see myself with devices like this, not at all! [... ] I cannot put myself to that level. That [speaking to the home] I have the impression that we look stupid.")

Similarly, almost all relatives found suitable (2/7) or very suitable (4/7) the voice control system for their loved one ("Because of his reduced vision, I find the voice command very convenient", "It's a great economy of movement and fatigue”). However, many relatives believe that this system is not immediately relevant as the level of autonomy of their relative is still good.

Regarding the caregivers opinion, they thought it would be easier for people to interact by voice. "The elderly are quickly overwhelmed when things are technical or technological [...] with vision problems [screen] is not easy.”. Moreover, they found it easier to use than touch-screen controls, and liked the fact that the person did not need to move thus avoiding potential falls.
Alerts Generated by the System In this scenario, the aim was to observe how people react when the system interrupts them to warn them about security problems, appointments or birthdays. These alerts were generated by the wizard in the middle of a conversation with the interviewer. They consisted in a female pre-recorded voice.

Regarding security, all seniors found good or very good that the system signals security issues. They admit they tend to forget to check whether the door is closed or the gas is turned off. Moreover, for some of them, this voice is a presence. However, they would not want it to happen too often. Half of seniors think that they would inform the system they have performed the action (door closed or gas turned off). "I would say I'm gonna do it latter". The other half would not like to do so and hope that the system would detect that the action was performed.

Almost all relatives (6/7) found the system well adapted to interacts with the senior ("Yes because she forgets more often certain things"). However, one relative did not like this feature because it reminded him of 'Big Brother'.

Regarding the appointment reminder, almost all seniors (6/8) did not like being informed by the system in this way because it gave them the feeling of being assisted. They are afraid they would not use their mind any more and thus lose some of their intellectual capacities if they do not train them.

Regarding the suddenness of the interruption, almost all (7/8) seniors prefer that the system emits a short sound before it speaks. This would allow them to be more attentive to what is going to be said and it would help to identify that it is the system which was speaking and not the television waking up or a person entering the house. For 5 participants, the sound must be different according to the alert. "Avec l'avertissement [le son] on se sent moins agressé par la voix."

("With the warning [sound] you feel less aggressed by the voice.")

"On sait que c'est la machine qui va parler et que c'est pas quelqu'un qui est rentré dans la maison"

("We know that it is the machine that is about to talk and that it's not someone who has entered the home").

Almost all the seniors (7/8) would be reassured to have such a system at home. Half of the relatives (4/7) would feel reassured if their relatives or friends had their home equipped. The other relatives (3/7) found that, at present, such a tool is not suitable and does not reassure them more than they already are. They believe that their parents are still capable enough to avoid security problems or to remember their appointments.

Half of seniors believed this system cannot be considered as decreasing autonomy. The other half thought otherwise. They are afraid of falling into inactivity. In contrast, the majority of the relatives (4/7) did not see this system functionality as making elderly dependent. On the contrary, 
they saw it as a way to reduce stress among the elderly, who are often afraid of not having the gas or doors closed. The system would avoid unnecessary movements to check something that was probably checked by the system and would reduce stress. However, two relatives perceived the interruption by the system as making elderly too dependent. These same relatives believe that this system is very suitable for people with disabilities.

The main concern raised by caregivers is the fact that such an interaction system could gradually replace carers. If carers are less present, the elderly will be more isolated. However, the 3 carers thought the system very suitable as it warns seniors about safety issues. The only downside is that the interruption is too brusque. "The way it happens is a little too ... [brutal] ". Carers do not think there is a risk of losing autonomy because it is a reminder, the system does not act for the elderly. However, for carers, it is important to make sure that the system does not start to think and do all the actions for the elderly. This correlates with the opinion of the seniors and relatives.

Communication with the Exterior With this scenario, the aim was to investigate how older people perceive communication with their loved ones using a webcam and a TV. Each senior was left alone watching TV when suddenly her relative started a conversation and appeared on the screen. All seniors found this mode of communication good (6/8) or very good (2/8). A similar trend was observed with relatives who found this mode of communication good (5/7) or very good (2/7). The elderly and relatives groups raised a few drawbacks. This mode of communication may be intrusive especially when the caller is not a close relative and this mode of interaction can be intimidating (for instance, people do not want to appear because they are not dressed). Apart from this, the elderly greatly appreciated the videoconference over the telephone because it looks almost like a visit. "Moi y a des journées je suis toute seule. Là c'est très bien parce que vous avez l'impression d'avoir une visite à la maison" ("There are days where I'm all alone. With this, it is very good because you feel you have a visit at home"). For the relatives, the main advantage is to see the physical or emotional state of the elderly. Indeed, by phone it is sometimes difficult to know whether the person is well or not, with the webcam they can realise if the person is tired, if she's not happy and did not dress, etc.

In a second part of the scenario, seniors were also asked whether they would find it interesting to answer the phone wherever they are in the house, that is to say, when the phone rings, they simply say "Décroche" ("Pick it up") and they can begin the conversation while circulating in the home. Almost all of them (7/8) would find it interesting to start a conversation when they have not yet reached the telephone receiver or television.
All carers found the video-conference mode of communication interesting for the elderly. All of them would be interested in communicating via a webcam with older people. They could see whether the person was really sick and if it were necessary to come sooner than planned. Regarding the possibility of having a phone conversation anywhere in the house, the carers think that can be highly useful because the elderly often forget where they left the handset and its research can be stressful and source of falls. "No need to go right across the flat to pick up".

Shared Calendar In this scenario, the aim was to investigate what the older people would think about an agenda that would be visible on the television. Almost all the elderly thought that the calendar would not be helpful $(2 / 8)$ or not helpful at all (5/8). Most people (4/8) do not wish to be notified of an appointment to come. To be informed of the next appointment, they would simply consult the classical printed calendar. Should they be told, they would prefer it to be via a visual message (4/8) rather than with a voice (2/8) (the problem is that the television is not always turned on). Relatives also found this type of agenda unhelpful (2/7) or not at all helpful (4/7) at present. They think this type of agenda is for dependant people. Most relatives (5/7) thought that the system should warn the elderly of a future appointment using a vocal message. Two carers also believed that people should be warned vocally.

\section{Overview and Discussion}

In this section, the main outcomes summarised during the debriefing phase are presented and discussed. The participants mainly stressed the interest of voice command and how this could improve security, autonomy and, to a smaller extend, could fight loneliness. However, they were very careful about privacy and clearly showed that they were very cautious of not accepting systems that would push them into a dependent situation. They want to keep control. Although only a small sample of seniors and relatives in healthy condition was recruited, this qualitative study confirmed the interest of voice-based technology for smart home and uncovered some pitfalls to avoid in its design.

Biases of the Study It must be emphasized that the study presents many biases that lower the generality of the findings. It was conducted with persons coming from only one area of France (the French Alps) and the sample is quite small. Moreover, it was not done in real in-situ conditions and the participants did not really 'live' with the system. However, the study was qualitative (and not quantitative), investigating the main bottlenecks and users' objections of the system being tested. We believe that at this stage of the system development, a larger size sample and real experimental 
conditions would not have improved greatly the user evaluation. In fact, some of our results are in accordance with large size surveys or long term experiments in other countries. Original questions regarding audio technology not covered in other studies have permitted to draw up a list of recommendations that will be integrated into the system and further tested in future experiments. Moreover, the Wizard of $\mathrm{Oz}$ approach made it possible to simulate a realistic context.

The experiment was done in co-discovery thus, seniors were always accompanied by a relative (except for one senior). This may have inhibited the senior according to her relationship with the relative. However, for this first contact with the system, it reassured both participants who were in an unknown situation (experimenter, video-camera, strange place... ) and favoured the projection of both. Moreover, the relatives' opinion was of great interest given that seniors often rely on a close relative to make decisions concerning their autonomy. Indeed, the involvement of the relatives tends to increase with the degree of dependence of the senior. The experiment has clearly emphasized the difference of points of view of these two categories.

Main Features Appreciated by the Participants During the debriefing, participants were asked to choose the functionalities they preferred. The participants answered straight after the experiment so they could easily remember the functionalities they appreciated the most. Seniors preferred mostly the voice command for the blinds and light (6), the system interventions about safety issues (4), the video-conferencing (1), and the check-list displayed on the screen (1). Relatives mostly liked the voice command for the blinds and light (5), the system interventions about safety issues (2) and the video-conferencing (2). The Carers mostly preferred the system interventions about safety issues (3) and the voice command (2). The voice command is the preferred feature of the system overall along with the interruptions about security issues. This confirms that a smart home fitted with speech processing technology is a promising technology that should be accepted by the elderly population.

Main Fears Provoked by the System Although the system was well received, it turned out that some functionalities provoked strong objections among the participants. The main fear of the elderly and relatives is the system failure. "Que ça ne marche pas et qu'on ne puisse pas le faire marcher autrement" ("That it does not work and that we can not get it to work in another way"). Very few seniors are afraid of being recorded via the microphones. Actually, for only two persons that remains a problem. However, during the interview one of them gave some hint that she had a personal problem related to audio recording in her life and the other one exposed a global point of view. "Ça, ça me pose problème. J'ai toujours l'impression qu'on sait tout ce qu'on fait qu'on a plus de liberté" ("That, I have a problem with it. I always feel everything is known, that we don't have freedom anymore"). Moreover, a surprising fear expressed by a senior was that anyone could use voice to command the system in her own home (an intruder for instance). In contrast, almost all seniors would refuse video cameras at home. Another main concern about the system is the fact that too much assistance would increase the dependence of the person by pushing her toward inactivity. "Faut compenser par des activités, veiller à faire des choses. Faut pas que ce soit une bonne raison pour ne plus rien faire" (" [When old] one must compensate by doing activities, make sure you do things. It must not be seen as a good reason for doing nothing"). This is accompanied by the fear that the system takes over everything. In addition, a related, though less clearly expressed fear, is the image that the person will render by living with such as system. A relative summarised his thought as : "On se sentirait un peu dégradé, en même temps ça pourrait être très utile mais je pense que quand on en arrive là c'est que physiquement y a un délabrement " ("It feels a bit degrading and at the same time it could be very useful but I think when it comes to such a point it means that physically there is a real decline”).

Regarding the carers, they also expressed concern about system failure. These failures would be really critical if the elderly are fully adapted to the system and do not know how to do without it. Moreover, they are afraid that such system would tend to gradually replace some of their visits and end up in making the seniors even more isolated.

Most of these fears can be addressed by a good design of the system. For instance, domotics systems can include several interaction modalities so that when one does not work, others can be used (e.g., voice recognition and classical switches). Moreover, given that the audio channel is devoted to recognizing orders, there is no need to conceive a system that records private audio data or sends it outside the house. Virtually everybody owns a telephone which is basically composed of a microphone connected to the outside world though there is no fundamental ethical question about privacy in its daily usage. SWEET-HOME would even be more respectful of privacy given that no link will exist between the raw signals and any internet connexion.

However, fear about a decrease in autonomy due to a system that can do everything is a subtle one. A system designed for active people in order to improve comfort, security and save time [26] may not be adapted to healthy but aged persons. For instance, saving time might no longer be a requirement when the person is retired.

Voice Interface As in other related studies [7], all participants found a strong interest in the voice interaction system. It is strongly preferred over a tactile system (or touchscreen) which would necessitate being physically available 
at the place the command is to be found or would imply to constantly know where the remote controller is. This is in line with other studies concerning personal emergency response systems which showed that push-button based control is not adapted to this population [17].

It is interesting to note that the 'key-word' form for commands is highly accepted (rather than the sentence based command). This would enable the system avoiding many of the current bottlenecks in speech recognition (e.g., ambiguity, complete sentence detection, etc.) [46] for a quicker development and acceptability of voice based domotics systems. In general, successful applications of speech recognition tend to have a small vocabulary. For instance, Hamill et al. [17] have used a speech-based dialogue system that can understand yes/no user's utterance and that showed promising results with 9 healthy young volunteers. This contrast with [14], who used a dialogue system coupled with speech understanding to allow more spontaneous command utterance. Their study showed that it is difficult to treat the numerous cases of out-of-vocabulary and ill-formed commands uttered by the user. In [20], audio information is used to identify situations at risk. They observed that even if the system is sometimes wrong in interpreting orders, most of the people are willing to continue using it. This is confirmed by other studies. For instance, in [7], a survey conducted among 200 intended users (50 to 80 years old) of a smart home for the elderly showed that people would tolerate some demands for repetitions in cases when the voice interface does not understand. However, for a reliable assessment of this notion of tolerance to repetition and the way the system provides solutions, it would have been necessary to place the subjects in real conditions for several days so that they were faced with several situations of system misunderstanding. For instance, in [38] an IVR was set to serve as medication reminder. 528 elderly persons were contacted and 99 participants accepted to take part to the study $(47.2 \%$ female, $93 \%$ over 60 , $72,7 \%$ were French speakers and $27.3 \%$ English speakers). However, only thirty-eight participants completed the experience. A major performance issue was that the voice recognition feature of IVR system did not recognize perfectly the participants' voices when uttering 'yes' or 'no'. They concluded that many participants were not receptive to the IVR technology due to technical issue. However, this experiment included mainly aged speakers while it is known that voice recognition performance decreases with age [2]. Moreover, the experimenters did not give details about how the speech recognizer has been tuned to this population.

Most of the participants found the voice interface natural. They also had tendency to prefer or to accept the 'tu' form (informal in French) to communicate with the system given this system would be their property. We are not aware of any study investigating this important aspect of acceptability (related to this is [14] who emphasized that elder Ger- mans tend to utter longer and politer commands than their fellow countrymen).

Regarding the system communication, half of the seniors would prefer a system with a female voice, one would rather hear a male voice but for the others, this did not matter. They were all unanimous about the fact that the voice system must be natural and not synthetic. This is in line with the findings of a study [29] investigating the preferences of 32 seniors (over 65) between synthetic and natural voice in different noise conditions. More than $93 \%$ preferred the natural voice.

Though system messages communicated via voice was not unanimously preferred by seniors and relatives, it was not completely rejected. Moreover, voice communication makes it possible to receive information while achieving a hand/eyes busy simultaneous task in any location in the home. This feature was unanimously found interesting by the professional caregivers.

Security is the Main Interest While the proposed system can bring more comfort and autonomy to daily life by providing an easy interaction with the domotics elements, the majority of the participants insisted on the security aspects. For instance, the voice interface would be of great use in case of falls. The elderly and their relatives have particularly appreciated that the system spares the elderly actions that can be dangerous (running to get the telephone handset, finding the switch in the middle of the night to turn on the light) and alerts them of dangerous situations (door opened, gas on, etc.). This trend is confirmed in almost all user evaluations involving elderly $[37,7,40]$ and by the dramatic number of research teams and companies working on fall detection [35]. Thus, smart homes for the elderly would be much more accepted if they contain features that can reassure them regarding security more than any other features whatever their initial condition and origin in developed countries are. In SwEET-Home, this aspect is treated in a different manner than classical distress detectors following the idiom 'An ounce of prevention is worth a pound of cure'. Rather than developing specialised fall or distress detectors, which are already being developed by a large research community, the system is designed to avoid hazardous situations. For instance, a lamp can be switched on in the middle of a dark night using the voice command rather than searching blindly for the switch or leaving the person walk in the dark. The generation of alert messages is also another example of prevention. Of course, this system is intended to complement distress situation detectors and not to replace them. They don't have the same aim.

Privacy must be Preserved Most of the participants found that this system does not put their privacy in danger. In fact, few seniors are afraid of being recorded. "Je crois que le 
bien-être que ça apporte, dépasse la crainte [d'être enregistrée]." ("I think that for the well-being it brings, it goes beyond the fear [of being recorded]"). In contrast, almost all seniors (7/8) would not want any camera at home. This is in line with [9] who interrogated 15 persons aged over 65 years about technology for smart home. All of them answered that video cameras are an issue regarding privacy. However, many smart home projects consider the video camera as a primary sensor $[19,24,37,52]$. This contradiction may be explained by the aim of each project. As emphasized by [40], the acceptance of technology varies with the distress or dependence situation of the person. For instance, in the Ageing-in-Place project [37], in which technology is used to assist seniors in a care retirement community, the authors recognized that although the residents do not appreciate the video cameras in their rooms, they feel more comfortable with it if they know that only rough silhouettes are analysed. Some methods to automatically hide private information [32] could also be accepted when video cameras are necessary. Actually, it is still unclear how video recording would be accepted among the population in their own home according to age, sex, dependency level, culture and degree of control of this recording. Even less studies exists regarding acceptability of applications based on microphones. Given that elderly people are human beings who have social activities, the privacy issue is not restricted solely to the permanent residents of a home but also to their relatives and any professional that may pay a visit. In our study, relatives and carers did not see the voice interface as a breach of privacy. In SWEET-HOME, the only video-camera involved is a web-cam used only for video-conferencing and which should be placed in a non intimate place and should be entirely controlled by the user.

Another potential infringement on privacy is the feeling of intrusion when the system suddenly interrupts the person to remind them an appointment. All groups (seniors, relatives, carers) found the interruption too intrusive and they recommended to warning the person using a short piece of music or sound in order to reassure the person. Indeed, without warning, the impression could be given that someone is in the house while the person thought they were alone and thus make them panic before they realised the voice was coming from the home. The information delivered in front of someone else was not questioned but may also be a privacy issue (the system should 'know' that the person is alone before delivering information or is using the telephone).

Another source of privacy issue was the shared calendar. Indeed elderly, relatives and carers would not enter the same kind of information so the participants did not like the idea of using the same system. For instance carers would like to enter confidential data that only other professional could read. "If the senior can read that the nurse wrote they were unwell they could panic. We are use to minimizing the problems in front of them to not worry them".

Finally, another issue which was too technical to be discussed with the participants at this stage is what will be done with the data? In smart home and ubiquitous environments, a new trend is to make the environment learn the person's activity, habits, etc. [33,16]. That requires recording personal data continuously to update the person's way of live model. How this data will be protected is an open question [1]. Many companies might have access to the home automation system to provide different services (e.g., cognitive training, shopping...) and might access private information (e.g., who is visiting, what is the favourite meal, music, etc.) to perform personalised advertising as is already the case with private information in mobile phones or on some social networks on the Internet. In SWEET-HOME, the system is designed not to record any critical information about the user's habit. The automatic speech recognizer will be composed of a small vocabulary such that no information about political opinion, feelings, etc. can be detected and no raw signals are planned to be stored.

Assistance, Compensation and Dependency The main objection that has been raised by seniors during the experiment is that, though of high interest and presenting nice features, the system is not adapted to their current needs because they are not dependent. This could be due to the fact that they do not want to render an image of assisted people but the relatives' opinion confirmed that this system would not be adapted to their current state. The older people have difficulty to project themselves with such systems at present but do recognize that it would fit a disabled person. Interest is therefore highly dependent on the level of autonomy and disability.

Several participants stressed the fact that one must be careful when developing such systems. Most of the participants live alone with frequent to rare visit. So, for some of them, making coffee, lowering the blinds, etc. represent important phases of the day that they are eager to perform. A domotics system would take away all these ritual activities and put them into a situation in which they feel useless. One participant summarised the life with such system as:

“J'aime bien agir plutôt que parler [...] J'aime bien fermer mes volets, etc. [...] Moi en ce moment je préfère faire les choses parce [que sinon] c'est glisser vers l'inactivité. Faudrait vraiment que je puisse plus le faire, parce que sinon on fait plus rien, on se couche et puis voilà."

("I like to act rather than talk [...] I like to close the blinds, etc. [...] I prefer to do things because otherwise it's going into inactivity. It should be that I can't do it any more, because otherwise we do nothing, we go to bed and that's that.") 
As confirmed in other studies in different countries [7, 1], the elderly fear that smart homes would decrease their autonomy rather than improving it. They want to continue as much as possible to perform activities that require physical and cognitive efforts in order to stay in good condition. We must thus ensure that the system would be limited to assistance. For instance, that it would give warnings in the case of potential problems but would not act in lieu of the elderly. The elderly want to continue to perform activities including those that are not risky. Assistances that have been recognized as useful by the relatives and the carers is the reminder of appointments or activity to do during the day. The designing of a smart home for a large elderly population rather than the disabled or frail population is thus a subtle task. On the one hand, it should provide more security and every day assistance and on the other hand it should be ready to compensate for some disabilities in cases when the person looses autonomy (e.g., after a fall, after a visual impairment) so that they are not perturbed by a new environment when back home after an accident. The aim is thus to adapt the smart home conception to their actual needs rather than imposing new technology on these people that may be a cause of dependency if not carefully thought out. This is in line with physiological and medical studies that showed that though improved control in the old age has significant positive impacts on health, inadequate provided control may lead to negative ones including stress and self-blame [41].

Apart, from security, an important topic for the elderly is loneliness. Many projects aim at building an intelligent companion in the form of a robot. For instance, RoboCare [4] and CompanionAble [3] projects aim at designing a robot to assist the elderly in their everyday tasks and to be company. One of our participants expressed her interest notably if the companion was able to speak. However, the robot technology for smart homes is still a research area for which the arrival date of an affordable and robust solution is unknown. Moreover, the integration of robots in our environment is not free from ethical issues and radical objections (e.g., the French nurse's trade union reaction [44] to the IWARD project [45]). Some of these approaches also hypothesised that having a companion, such as a virtual assistant [11] would make it possible to personify the control of the home. But during the voice interaction, the elderly seemed to prefer to communicate with the house in general rather than with a specific object (virtal agent or robot). However, we did not have any system to show and other studies [7] showed that elderly people who were firstly reluctant have been easily convinced of the interest of such a virtual assistant by other seniors during a focus group discussion. The approach taken in SWEET-HOME to address the question of loneliness was to adopt existing commercialised systems such as e-lio by Technosens and Visage by Camera-Contact, in order to benefit from their state-of-the- art domotics technology and their years of experience in developing communication systems for the elderly. The participants all very much appreciated being able to communicate with their relatives through videoconferencing, which made them feel closer to the person they were communicating with than does a simple phone call, and this feeling of closeness to others is something which is often lacking in the life of seniors who are frequently all alone.

\section{Conclusion}

This paper presents the result of an experiment that aimed at assessing the acceptability of a smart home equipped with audio processing technology. The technology in question is developed within the SWEET-HOME project which aims at providing voice command within smart homes. The target users are autonomous elderly people living alone in their home to support them during they daily life. The experiment took place in a real smart home so that participants were able to discover and interact with the environment under consideration. The experiment involved 8 single perfectly autonomous elderly between 75 and 88 years old and 7 of their close relatives. The experiment was composed of Wizard of $\mathrm{Oz}$ phases followed by interviews in co-discovery. The outcomes of the experiment showed that speech technology has a great potential to ease everyday life for the elderly. Moreover, it appeared that most of the needs of the elderly people are linked to reassurance and better security at home. The participants particularly appreciated the fact that this speech technology can bring more security by warning in case of hazardous situations or by allowing people to call for help in case of a fall. Comfort improvement was only an ancillary preoccupation. Surprisingly, while the system was supposed to bring more independence, it raised concern in the aged population that such a system would make them less autonomous by encouraging a lazy lifestyle and provoking quicker degradation of health condition. Smart home technology design must thus be careful to avoid designing systems that might actually promote an unhealthy way of living. As pointed out by Augusto [1], researchers and developers should consider that users are at the centre and that technology should be adapted to their needs and not the reverse.

The main weakness of the study is that it was restricted to a small sample of participants. However, to the best of our knowledge no user evaluation has ever been conducted in a smart home with voice command using a Wizard of $\mathrm{OZ}$ technique and a senior/relative co-discovery approach. The co-discovery approach imposed further constraints on the recruitment but allowed a dialogue between the seniors and their accompanying relative so that they felt more confident during the experiment and made the evaluation of acceptance more realistic. For instance, the seniors care about 
the image they can render while the relatives are more interested in knowing how well the person is. Future work will include testing the actual system with more participants and increasing robustness of the audio processing.

Acknowledgements The authors would like to thank the participants (seniors, relatives and carers) who accepted to perform this experiment and kindly gave their time and Nicolas Bonnefond for being such a good wizard. Thanks are extended to Thierry Chevalier for his help in defining the protocol and to our reviewer for checking the English of the early draft.

\section{References}

1. Augusto, J.C.: Past, present and future of ambient intelligence and smart environments. In: ICAART, pp. 11-18 (2009)

2. Baba, A., Yoshizawa, S., Yamada, M., Lee, A., Shikano, K.: Acoustic models of the elderly for large-vocabulary continuous speech recognition. Electronics and Communications in Japan, Part 2, Vol. 87, No. 7, 2004 87(2), 49-57 (2004)

3. Badii, A., Boudy, J.: CompanionAble - integrated cognitive assistive \& domotic companion robotic systems for ability \& security. In: 1st Congres of the Société Française des Technologies pour l'Autonomie et de Gérontechnologie (SFTAG'09), pp. 1820. Troyes (2009)

4. Bahadori, S., Cesta, A., Grisetti, G., Iocchi, L., Leone, R., Nardi, D., Oddi, A., Pecora, F., Rasconi, R.: RoboCare: Pervasive Intelligence for the Domestic Care of the Elderly. Intelligenza Artificiale 1(1), 16-21 (2004)

5. Bender, B.G., Apter, A., Bogen, D.K., Dickinson, P., Fisher, L., Wamboldt, F.S., Westfall, J.M.: Test of an interactive voice response intervention to improve adherence to controller medications in adults with asthma. The Journal of the American Board of Family Medicine 23(2), 159-165 (2010)

6. Blanpain, N., Chardon, O.: Projections de population à l'horizon 2060: Un tiers de la population âgé de plus de 60 ans. Institut national de la statistique et des études économiques (France) (2010). [in French]

7. Callejas, Z., López-Cózar, R.: Designing smart home interfaces for the elderly. SIGACCESS Newsletter 95 (2009)

8. Chan, M., Campo, E., Estève, D., Fourniols, J.Y.: Smart homes current features and future perspectives. Maturitas 64(2), 90-97 (2009)

9. Demiris, G., Rantz, M., Aud, M., Marek, K., Tyrer, H., Skubic, M., Hussam, A.: Older adults' attitudes towards and perceptions of "smart home" technologies: a pilot study. Medical Informatics and the Internet in Medicine 29(2), 87-94 (2004)

10. Edwards, W., Grinter, R.: At home with ubiquitous computing: Seven challenges. In: G. Abowd, B. Brumitt, S. Shafer (eds.) Ubicomp 2001: Ubiquitous Computing, Lecture Notes in Computer Science, vol. 2201, pp. 256-272. Springer Berlin / Heidelberg (2001)

11. Filho, G., Moir, T.J.: From science fiction to science fact: a smarthouse interface using speech technology and a photo-realistic avatar. International Journal of Computer Applications in Technology 39(8), 32-39 (2010)

12. Fleury, A., Vacher, M., Noury, N.: SVM-based multi-modal classification of activities of daily living in health smart homes: Sensors, algorithms and first experimental results. IEEE Transactions on Information Technology in Biomedicine 14(2), 274 -283 (2010)

13. Fugger, E., Prazak, B., Hanke, S., Wassertheurer, S.: Requirements and ethical issues for sensor-augmented environments in elderly care. In: 4th International Conference on Universal Access in Human-Computer Interaction, pp. 887-893 (2007)
14. Gödde, F., Möller, S., Engelbrecht, K.P., Kühnel, C., Schleicher, R., Naumann, A., Wolters, M.: Study of a speech-based smart home system with older users. In: International Workshop on Intelligent User Interfaces for Ambient Assisted Living, pp. 17-22 (2008)

15. Gordon, M.: Community care for the elderly: is it really better? Canadian Medical Association Journal 148, 393-396 (1993)

16. Hagras, H., Doctor, F., Lopez, A., Callaghan, V.: An incremental adaptive life long learning approach for type-2 fuzzy embedded agents in ambient intelligent environments. IEEE Transactions on Fuzzy Systems 15(1), 41-55 (2007)

17. Hamill, M., Young, V., Boger, J., Mihailidis, A.: Development of an automated speech recognition interface for personal emergency response systems. Journal of NeuroEngineering and Rehabilitation 6 (2009)

18. Hornbrook, M., Stevens, V., Wingfield, D., Hollis, J., Greenlick, M., Ory, M.: Preventing falls among community-dwelling older persons: results from a randomized trial. Gerontologist 34(1), 1623 (1994)

19. Intille, S.S.: Designing a home of the future. IEEE Pervasive Computing 1(2), 76-82 (2002)

20. Istrate, D., Vacher, M., Serignat, J.F.: Embedded implementation of distress situation identification through sound analysis. The Journal on Information Technology in Healthcare 6, 204-211 (2008)

21. Jaimes, A., Sebe, N., Gatica-Perez, D.: Human-centered computing: a multimedia perspective. In: MULTIMEDIA '06: Proceedings of the 14th annual ACM international conference on Multimedia, pp. 855-864. ACM, New York, NY, USA (2006)

22. Jambon, F.: Human-Computer Interaction and Innovation in Handheld, Mobile and Wearable Technologies, pp. 155-171. IGI Global (2011)

23. Kang, M.S., Kim, K.M., Kim, H.C.: A questionnaire study for the design of smart home for the elderly. In: Healthcom, pp. 265-268 (2006)

24. Keshavarz, A., Tabar, A.M., Aghajan, H.: Distributed vision-based reasoning for smart home care. In: ACM SenSys Workshop on Distributed Smart Cameras (2006)

25. Kjeldskov, J., Skov, M.B.: Studying usability in sitro: Simulating real world phenomena in controlled environments. International Journal of Human-Computer Interaction 22(1\&2), 7-36 (2007)

26. Koskela, T., Väänänen-Vainio-Mattila，K.: Evolution towards smart home environments: empirical evaluation of three user interfaces. Personal and Ubiquitous Computing 8, 234-240 (2004)

27. Le, X.H.B., Di Mascolo, M., Gouin, A., Noury, N.: Health Smart Home for elders - A tool for automatic recognition of activities of daily living. In: Proceedings of the 30th Annual International Conference of the IEEE Engineering in Medicine and Biology Society - EMBC, p. 10. Vancouver Canada (2008)

28. Lecouteux, B., Vacher, M., Portet, F.: Distant speech recognition in a smart home: Comparison of several multisource ASRs in realistic conditions. In: Interspeech 2011, pp. 2273-2276. Florence, Italy (2011)

29. Lines, L., Hone, K.S.: Multiple voices, multiple choices: Older adults' evaluation of speech output to support independent living. Gerontechnology Journal 5(2), 78-91 (2006)

30. López-Cózar, R., Callejas, Z.: Multimodal dialogue for ambient intelligence and smart environments. In: H. Nakashima, H. Aghajan, J.C. Augusto (eds.) Handbook of Ambient Intelligence and Smart Environments, pp. 559-579. Springer US (2010)

31. Marek, K., Rantz, M.: Aging in place: a new model for long-term care. Nursing Administration Quarterly 24(3), 1-11 (2000)

32. Moncrieff, S., Venkatesh, S., West, G.A.W.: Dynamic privacy in a smart house environment. In: IEEE Multimedia and Expo, pp. 2034-2037 (2007)

33. Mozer, M.C.: Smart environments: Technologies, protocols, and applications. J. Wiley \& Sons (2005) 
34. Mäyrä, F., Soronen, A., Vanhala, J., Mikkonen, J., Zakrzewski, M., Koskinen, I., Kuusela, K.: Probing a proactive home: Challenges in researching and designing everyday smart environments. $\mathrm{Hu}-$ man Technology 2, 158-186 (2006)

35. Noury, N., Rumeau, P., Bourke, A., ÓLaighin, G., Lundy, J.: A proposal for the classification and evaluation of fall detectors. IRBM 29(6), 340-349 (2008)

36. Popescu, M., Li, Y., Skubic, M., Rantz, M.: An acoustic fall detector system that uses sound height information to reduce the false alarm rate. In: Proc. 30th Annual Int. Conference of the IEEEEMBS 2008, pp. 4628-4631 (2008)

37. Rantz, M., Porter, R., Cheshier, D., Otto, D., Servey, C., Johnson, R., Aud, M., Skubic, M., Tyrer, H., He, Z., Demiris, G., Alexander, G., Taylor, G.: TigerPlace, a State-Academic-Private project to revolutionize traditional Long-Term care. Journal of Housing For the Elderly 22(1), 66 (2008)

38. Reidel, K., Tamblyn, R., Patel, V., Huang, A.: Pilot study of an interactive voice response system to improve medication refill compliance. BMC Medical Informatics and Decision Making 8, 46 (2008)

39. Rialle, V., Noury, F.D.N., Bajolle, L., Demongeot, J.: Health "smart" home: information technology for patients at home. Telemed J E Health 8(4), 395-409 (2002)

40. Rialle, V., Ollivet, C., Guigui, C., Hervé, C.: What do family caregivers of alzheimer's disease patients desire in smart home technologies? contrasted results of a wide survey. Methods of Information in Medicine 47(1), 63-69 (2008)

41. Rodin, J.: Aging and health: effects of the sense of control. Science 233(4770), 1271-1276 (1986)

42. Rougui, J., Istrate, D., Souidene, W.: Audio sound event identification for distress situations and context awareness. In: 31st Annual International Conference of the IEEE Engineering in Medicine and Biology Society (EMBC'09), pp. 3501-3504. Minneapolis, USA (2009)

43. Slavík, P., Němec, V., Sporka, A.: Speech based user interface for users with special needs. In: V. Matoušek, P. Mautner, T. Pavelka (eds.) Text, Speech and Dialogue, Lecture Notes in Computer Science, vol. 3658, pp. 743-743. Springer Berlin / Heidelberg (2005)

44. Syndicat National des Professionnels Infirmiers: Délires technologiques : les "robots infirmiers". http://www.syndicat-infirmier.com/Delires-technologiques-les-robots.html (2007). [in French]

45. Szecsi, T., Mamun, K., Hasan, K., Islam, A., Griffin, C., Hoque, M.: Hospital robot module development in the iward project. In: 6th CIRP International Conference on Intelligent Computation in Manufacturing Engineering (CIRP ICME '08). Naples, Italy (2008)

46. Vacher, M., Fleury, A., Portet, F., Serignat, J.F., Noury, N.: Complete Sound and Speech Recognition System for Health Smart Homes: Application to the Recognition of Activities of Daily Living, pp. 645 - 673. Intech Book (2010)

47. Vacher, M., Istrate, D., Portet, F., Joubert, T., Chevalier, T., Smidtas, S., Meillon, B., Lecouteux, B., Sehili, M., Chahuara, P., Méniard, S.: The sweet-home project: Audio technology in smart homes to improve well-being and reliance. In: 33rd Annual International Conference of the IEEE Engineering in Medicine and Biology Society (EMBC'11), p. 4 (2011)

48. Vacher, M., Portet, F., Fleury, A., Noury, N.: Development of audio sensing technology for ambient assisted living: Applications and challenges. International Journal of E-Health and Medical Communications 2(1), 35 - 54 (2011)

49. Weiser, M.: The computer for the 21 st century. Scientific American 265(3), 66-75 (1991)

50. Zajicek, M.: Interface design for older adults. In: WUAUC'01: Proceedings of the 2001 EC/NSF workshop on Universal accessibility of ubiquitous computing, pp. 60-65. ACM, New York, NY, USA (2001)
51. Ziefle, M., Wilkowska, W.: Technology acceptability for medical assistance. In: pervasivehealth (2010)

52. Zouba, N., Bremond, F., Thonnat, M., Anfosso, A., Pascual, E., Mallea, P., Mailland, V., Guerin, O.: A computer system to monitor older adults at home: Preliminary results. Gerontechnology Journal 8(3), 129-139 (2009) 